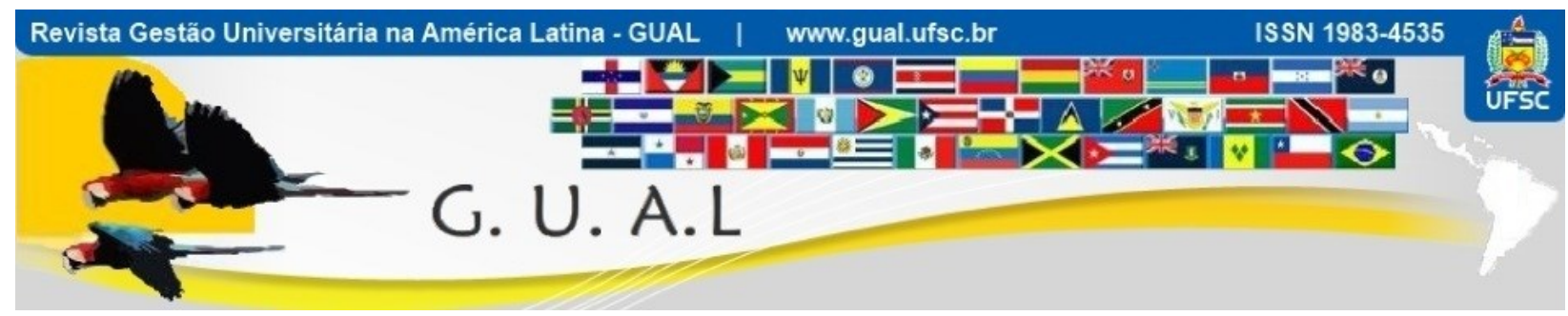

DOI: http://dx.doi.org/10.5007/1983-4535.2018v11n3p166

\title{
OS VALORES RELATIVOS AO TRABALHO E O ENTRINCHEIRAMENTO ORGANIZACIONAL DOS SERVIDORES DE UMA UNIVERSIDADE PÚBLICA
}

\section{WORK VALUES AND ORGANIZATIONAL ENTRENCHMENT OF A PUBLIC UNIVERSITY WORKERS}

Sarah Renata Menezes e Silva, Mestranda

Universidade Federal de Ceará - UFC

srenata.ms@gmail.com

Luis Eduardo Brandão Paiva, Doutorando Universidade Federal de Ceará - UFC edubrandas@gmail.com

Tereza Cristina Batista de Lima, Doutora Universidade Federal de Ceará - UFC tcblima@uol.com.br

Recebido em 14/fevereiro/2018

Aprovado em 05/agosto/2018

Sistema de Avaliação: Double Blind Review 


\title{
RESUMO
}

Este estudo tem como objetivo analisar a relação entre os valores relativos ao trabalho e o entrincheiramento organizacional dos servidores de uma universidade pública. Adicionalmente, pretende-se comparar os valores relativos ao trabalho e o entrincheiramento organizacional entre os docentes e os técnicos administrativos. Diante disso, tem-se uma pesquisa quantitativa, de natureza descritiva, junto a 384 servidores de uma universidade pública, em que foram adotadas duas escalas previamente validadas: a Escala Revisada de Valores Relativos ao Trabalho, de Porto e Pilati (2010); e a Escala de Entrincheiramento Organizacional, de Rodrigues e Bastos (2012). Para o tratamento dos dados, utilizou-se a estatística descritiva, inferencial (teste $t$ e teste de Mann-Whitney) e a correlação de Spearman. Os resultados indicam que existem relações positivas entre ajustamento à posição social e realização; entre arranjos burocráticos impessoais e universalismo e benevolência; e entre limitação de alternativas e conformidade; e relações negativas entre arranjos burocráticos impessoais e segurança; e entre limitação de alternativas e segurança. De modo geral, os técnicos administrativos sentem mais restrições a empregabilidade do que os docentes, e estes, por sua vez, priorizam mais autoridade, riqueza, reconhecimento social e autoridade, ao compará-los com os técnicos administrativo.

Palavras chave: Entrincheiramento Organizacional. Serviço Público. Valores Relativos ao Trabalho.

\begin{abstract}
This study aims to analyze the relationship between the values relating to work and the organizational entrenchment of the servers of a public university. Additionally, it is intended to compare the values related to work and organizational entrenchment between teachers and administrative technicians. In view of this, there is a quantitative research, of a descriptive nature, with 384 employees of a public university, in which two previously validated scales were adopted: the Revised Scale of Values Relating to Work, of Porto and Pilati (2010); and the Organizational Entrenchment Scale, of Rodrigues and Bastos (2012). For the data treatment, descriptive, inferential statistics (t-test and Mann-Whitney test) and Spearman's correlation were used. The results indicate that there are positive relations between adjustment to social position and achievement; between impersonal bureaucratic arrangements and universalism and benevolence; and between limitation of alternatives and compliance; and negative relationships between impersonal bureaucratic arrangements and security; and between limitation of alternatives and safety. In general, administrative technicians feel more employability constraints than do teachers, and teachers, in turn, prioritize more authority, wealth, social recognition, and authority by comparing them with administrative technicians.
\end{abstract}

Keywords: Organizational Entrenchment. Public Service. Values Relating To Work. 


\section{INTRODUÇÃO}

No ambiente de trabalho existem relações de troca entre o empregado e o empregador, em que ocorre uma permuta, os trabalhadores oferecem desempenho, assiduidade, permanência e colaboração espontânea; e as organizações concedem incentivos (retribuições econômicas, financeiras, materiais e sociais) para atrair, manter e motivar os funcionários no ambiente organizacional (MINER, 2015; SIQUEIRA; PADOVAM, 2008).

O trabalho, diante de uma variedade de significados, constitui-se como um meio para que os indivíduos possam atingir suas metas pessoais, sendo também um dos elementos centrais da identidade social dos indivíduos. Os valores do trabalho tendem a influenciar a relação entre as pessoas e as organizações, possibilitando, então, o comprometimento do indivíduo com a organização (CAMARA et al., 2015; PORTO; TAMAYO, 2008; PORTO; PILATI, 2010), sobretudo o comprometimento afetivo, o que mais se relaciona com os valores, conforme apontam Martins e Sant'Anna (2014), e isto impacta diretamente nos resultados organizacionais.

O conceito de entrincheiramento na carreira foi trazido, primordialmente, por Carson, Carson e Bedeian (1995), os quais definem que o indivíduo tende a permanecer na organização a qual trabalha por motivos de investimentos feitos - ligados a custos pessoais e emocionais - assim como devido à pouca percepção de alternativas fora daquele ambiente de trabalho. O entrincheiramento organizacional surge com a necessidade de investigar fatores que eram considerados parte do comprometimento, ampliando, assim, a precisão conceitual e empírica dos constructos que compõem os vínculos do indivíduo com a organização, como ajustamentos à posição social, arranjos burocráticos impessoais e limitação de alternativas (CARSON; BEDEIAN, 1994; RODRIGUES; BASTOS, 2012).

Em relação aos valores relativos ao trabalho, verifica-se, no contexto nacional, a compreensão dos elementos motivacionais que influenciam a escolha profissional dos indivíduos, a satisfação laboral e o comportamento produtivo (PORTO; PILATI, 2010). Os valores relativos ao trabalho direcionam a vida dos indivíduos no ambiente organizacional e, consequentemente, tendem a interferir na gestão e no comportamento do indivíduo na organização (JIN; ROUNDS, 2012; PORTO; PILATI, 2010).

Levando em consideração que os estudos dos valores relativos ao trabalho visam o entendimento daquilo que é considerado importante para os trabalhadores no ambiente laboral, assim como se referem à compreensão das razões que os levam a trabalhar 
(ANDRADE et al., 2018; PORTO; TAMAYO, 2008); e que o modelo teórico de entrincheiramento organizacional, proposto por Rodrigues e Bastos (2013), parte da trajetória do indivíduo na organização, de sua concepção acerca dos investimentos feitos até então e do que ele viria a perder caso saísse da organização; este estudo dispõe-se, então, a responder ao seguinte questionamento: qual a relação entre os valores do trabalho e o entrincheiramento organizacional dos servidores de uma universidade pública?

Esta pesquisa tem como objetivo geral, portanto, analisar a relação entre os valores relativos ao trabalho e o entrincheiramento organizacional dos servidores de uma universidade pública. Adicionalmente, pretende-se comparar os valores relativos ao trabalho e o entrincheiramento organizacional entre os docentes e os técnicos administrativos. É pertinente enfatizar que as universidades, que disseminam conhecimentos para a sociedade (TECCHIO et al., 2013), são formadoras de capital humano, geradoras de conhecimento e, diante disso, devem acompanhar as mudanças organizacionais - conhecendo os seus servidores e as relações entre o trabalho e o desempenho institucional dos funcionários (PAIVA; FERRAZ, 2013),

No Brasil, ainda são escassos os estudos sobre valores relativos ao trabalho versus entrincheiramento organizacional (CAMARA et al., 2015; PORTO; PILATI, 2010). A escala de entrincheiramento organizacional tem sido utilizada em investigações com relações entre o entrincheiramento e a carreira ou motivação ou comprometimento, por exemplo (BAIOCCHI; MAGALHÃES, 2004; BALSAN et al., 2016; MAGALHÃES; GOMES, 2007). Diante de pesquisas em grandes portais de periódicos, como Spell e Scielo, verificam-se poucos estudos que ampliem a compreensão da dinâmica de fenômenos micro organizacionais e comportamentais dos servidores públicos, a exemplo da relação entre os valores relativos ao trabalho e o entrincheiramento organizacional (RODRIGUES; BASTOS, 2013).

Destarte, o estudo procura suplantar essa lacuna da literatura, alinhando os valores relativos ao trabalho ao entrincheiramento organizacional na percepção dos servidores de uma universidade pública, a fim de fornecer suporte para um melhor entendimento acerca desses aspectos na visão dos servidores, considerando, então, os docentes e técnico-administrativos. 


\section{REVISÃO DA LITERATURA}

\subsection{VALORES RELATIVOS AO TRABALHO}

Os valores são definidos como crenças que orientam as ações, as quais servem como padrões ou critérios referentes a metas desejáveis, transcendendo situações específicas e obedecendo critérios de importância (SCHWARTZ, 2012). O sistema de valores está disposto em dois níveis: (a) uma estrutura geral, ampla e abstrata, relacionada a todos os aspectos da vida; e (b) estruturas associadas a contextos específicos, resultantes da aplicação dos valores a situações cotidianas, que favorecem o entendimento de como os valores estão relacionados à tomada de decisão concreta (TAMAYO; PORTO, 2003).

Tamayo e Porto (2003) definem valores relativos ao trabalho como crenças ou princípios de indivíduos, hierarquicamente organizados, sobre metas ou recompensas desejáveis por meio do trabalho, que orientam suas avaliações sobre resultados, contexto laboral, comportamento e escolhas de alternativas de trabalho. Ainda segundo esses autores, são três os aspectos relevantes para o conceito: (a) cognitivo - são crenças sobre o que é desejável ou não; (b) motivacional - declaram atração e vontade do indivíduo em relação ao trabalho; e (c) hierárquico - são avaliados em uma escala de importância.

Levando-se em conta a perspectiva de Schwartz (2012), o que distingue um valor de outro é o tipo de meta ou motivação que expressa. Schwartz (2012) sugere, então, dez valores amplos de acordo com a motivação subjacente a cada um deles, dispondo-os em uma estrutura bidimensional, conforme pode-se observar pela Figura 1 - abertura à mudança (hedonismo, estimulação e autodeterminação) versus conservadorismo (segurança, conformidade e tradição); e autopromoção (poder, realização) versus autotranscedência (universalismo e benevolência).

Com base nessa estrutura de dez valores gerais proposta por Schwartz (1992), Tamayo e Porto (2003) elaboraram a Escala de Valores Relativos ao Trabalho (EVT), posteriormente revisada (EVT-R) por Porto e Pilati (2010). Portanto, os fatores da EVT-R correspondem aos valores de autodeterminação, estimulação, poder, realização, segurança, conformidade, universalismo e benevolência da teoria geral de valores humanos.

Pesquisas recentes buscam estabelecer a hierarquia de valores dos indivíduos (CAMMAROSANO; SANTOS; ROJAS, 2014; CARVALHO et al., 2014; PAIVA; FERRAZ, 2013), demonstrando ainda a influência dos valores do trabalho no comportamento 
das pessoas, bem como no modo como as pessoas se relacionam com as organizações. Isso evidencia a existência de correspondência com outros constructos, tais como o comprometimento afetivo, instrumental e normativo (CAMARA et al., 2015), a satisfação (FERREIRA; FERRAZ; COSTA, 2015), os valores organizacionais (SOUSA; PORTO, 2016), a cidadania organizacional (ANDRADE et al., 2017) e as âncoras de carreira (ANDRADE et al., 2018).

Figura 1 Modelo teórico de relações entre dez tipos motivacionais de valor

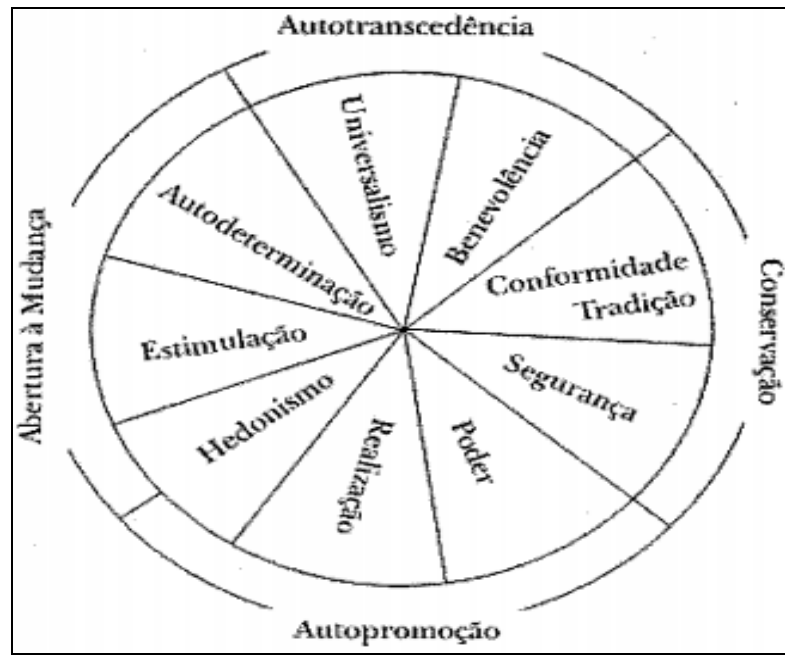

Fonte: Porto e Tamayo (2012), adaptado de Schwartz (2012, p. 9).

A partir da EVT-R, os autores sugerem o desenvolvimento de pesquisas que permitam compreender a dinâmica desses valores no estabelecimento de vínculos no trabalho (PORTO; PILATI, 2010), como o entrincheiramento organizacional, por exemplo - o que mostra indicativos para o desenvolvimento desta pesquisa, detendo-se da relação entre os valores relativos ao trabalho e o entrincheiramento organizacional.

\subsection{ENTRINCHEIRAMENTO ORGANIZACIONAL}

O Entrincheiramento Organizacional (EO) surge da discussão sobre os problemas conceituais e empíricos do modelo tridimensional de comprometimento organizacional, proposto por Meyer e Allen (1991), e da sugestão de que a dimensão de continuação seja retirada desse modelo.

Segundo Carvalho et al. (2011), a falta de consenso na conceituação e as dificuldades na mensuração do comprometimento organizacional conduzem ao aparecimento de diversas definições de comprometimento organizacional. Já para Rodrigues e Bastos (2010), sua 
mensuração não está devidamente equacionada, existindo inúmeras escalas, nem sempre bem delimitadas conceitualmente, em que ocorre uma propensão a considerar comprometimento organizacional como fonte de vínculos diversos entre o indivíduo e a organização, o que provoca falta de precisão nas pesquisas, dilatação do construto e prejuízo à validade dos resultados encontrados.

Uma das importantes contribuições para a definição de entrincheiramento organizacional é atribuída a Becker (1960) e sua teoria dos side bets, ou seja, o aprisionamento pelas trocas laterais, sacrifícios e investimentos realizados ao longo do tempo. Entretanto, o entrincheiramento foi abordado, inicialmente, no contexto da carreira, por Carson, Carson e Bedeian (1995). Esses autores ainda o definem como sendo uma perspectiva de continuidade, em que os indivíduos permanecem em uma ocupação por causa das recompensas extrínsecas associadas a uma carreira, assim como das perdas incorridas ao desistir. A proposta é de três dimensões para o constructo: (a) investimentos de carreira, referente aos investimentos acumulados que seriam perdidos ou julgados sem valor se houvesse uma mudança; (b) custos emocionais, associados à busca de uma nova profissão; e (c) limitação de alternativas, relativo à percepção de falta de opções disponíveis.

Baseados na teoria dos side bets, proposta por Becker (1960), e no entrincheiramento na carreira, sugerido por Carson, Carson e Bedeian (1995); Rodrigues e Bastos (2013) propõem a análise do entrincheiramento a partir da perspectiva organizacional, conceituandoo como a tendência do trabalhador a permanecer na organização devido a sua avaliação acerca de sua empregabilidade, de suas alternativas fora da organização e dos custos que podem estar associados a sua saída (RODRIGUES; BASTOS, 2013).

Os autores sugerem três dimensões para EO (RODRIGUES; BASTOS, 2013):

- Ajustamentos à posição social (APS): referem-se aos investimentos feitos para a adaptação à posição em que o indivíduo se encontra e às condições necessárias para o bom desempenho, os quais serão perdidos em caso de saída. Incluem qualquer processo que faça com que o indivíduo se desenvolva na organização, tais como programas de treinamento e desenvolvimento e cursos de formação. O indivíduo atinge um status que influencia sua rede de relacionamento social ao passo em que é treinado e desenvolvido. Isso faz com que ele seja reconhecido pela competência;

- Arranjos burocráticos impessoais (ABI): estão associados a ganhos materiais, estabilidade financeira e funcional e benefícios perdidos com a saída;

- Limitação de alternativas (LA): diz respeito à percepção de restrições de empregabilidade, fazendo com que o indivíduo se sinta preso. 
Pesquisas têm evidenciado uma possível sobreposição entre o comprometimento de continuação e o entrincheiramento (BALSAN et al., 2016; BLAU, 2001; BLAU; HOLLADAY, 2006; RODRIGUES; BASTOS, 2013), apontando-se fortes correlações entre esses constructos, sugerindo, então, que ambos compartilham os mesmos antecedentes (CARVALHO et al., 2011). Dessa forma, alguns autores propõem que o comprometimento retorne à perspectiva unidimensional de base afetiva, consolidada na obra de Mowday, Porter e Steers (1982), considerando-se as outras duas bases como vínculos distintos entre indivíduo e organização (BLAU, 2001; CARVALHO et al., 2011; KLEIN; MOLLOY; COOPER, 2009; RODRIGUES; BASTOS, 2012; SOLINGER; OLFFEN; ROE, 2008).

A agenda de pesquisa sobre entrincheiramento organizacional tem buscado testar sua sobreposição ao comprometimento organizacional (RODRIGUES; BASTOS, 2010); compreender como se constrói e se desenvolve esse vínculo (RODRIGUES et al., 2013); analisar perfis de entrincheiramento (SILVA; LIMA; LEONE, 2015); verificar sua relação com variáveis demográficas (RODRIGUES; BASTOS, 2013), entre outros fatores, tais como a percepção sobre práticas de gestão de recursos humanos (SCHEIBLE; BASTOS, 2013), a satisfação no trabalho (MEIRELES; LEMOS; BALASSIANO, 2015) e o modelo de gestão agency-community (SILVA et al., 2017).

Rodrigues e Bastos (2012) sugerem a realização de estudos descritivos que avaliem o nível de entrincheiramento organizacional em amostras de diferentes ocupações ou segmentos, bem como na análise de seus antecedentes e consequentes. Esta pesquisa está inserida nesse contexto, ao explorar as relações entre os valores relativos ao trabalho e o entrincheiramento organizacional na perspectiva dos servidores de uma universidade pública.

\section{PROCEDIMENTOS METODOLÓGICOS}

Considera-se a classificação proposta para este estudo por Collis e Hussey (2005), detendo-se de uma pesquisa quantitativa, de natureza descritiva, pois possibilita a identificação de aspectos de determinada população - servidores de uma universidade pública. Para a coleta dos dados, utiliza-se um survey, o qual possibilita apontar fontes de eventos, elaborar um modelo lógico, verificar a importância de cada fator, bem como analisar as possíveis correlações existentes entre as variáveis (COOPER; SCHINDLER, 2016).

$\mathrm{O}$ universo da pesquisa é composto pelos servidores técnicos administrativos e docentes de uma universidade pública do Estado do Ceará. A instituição investigada conta 
com 5515 servidores (2082 docentes e 3433 técnicos administrativos) e 28000 alunos matriculados, distribuídos entre os seus sete campi. Essa instituição é considerada a melhor do Norte e Nordeste, sendo ainda configurada entre as 15 melhores do Brasil, e isto justifica a escolha desta instituição para o universo investigado.

A amostragem não probabilística se deu por acessibilidade e conveniência dos pesquisadores, tomando-se como critério de escolha a disponibilidade do respondente em participar da pesquisa. Foi obtida, então, uma amostra de 384 indivíduos (com nível de confiança de $99 \%$ e margem de erro de 6,7\%), o que se pode inferir uma amostra satisfatória para representar a população.

A coleta de dados foi realizada no período de 10 a 20 de abril de 2017 , por meio de questionário impresso e online - composto por questões sociodemográficas e duas escalas previamente validadas: a Escala Revisada de Valores Relativos ao Trabalho (EVT-R), de Porto e Pilati (2010); e a versão reduzida da Escala de Entrincheiramento Organizacional (EEO), de Rodrigues e Bastos (2012), ambas estruturadas diante de um conjunto de itens preestabelecidos, constituídos em uma escala Likert de 5 pontos, a primeira variando entre "nada importante" e "extremamente importante"; e a segunda entre "discordo totalmente" e "concordo totalmente". A EVT-R é composta por 34 itens, agrupados nas seguintes regiões ou tipos motivacionais: autodeterminação/estimulação, segurança, realização, poder, conformidade e universalismo/benevolência. Já a versão reduzida da EEO é formada por 18 itens, distribuídos em 3 dimensões: ajustamentos à posição social (APS), arranjos burocráticos impessoais (ABI) e limitação de alternativas (LA).

As técnicas de análises estatísticas dos dados aplicadas foram a estatística descritiva e inferencial (teste $\mathrm{t}$ e teste de Mann-Whitney); o Alfa de Cronbach - que mensura a confiabilidade interna dos itens na dimensão (quanto mais próximo de 1 , maior a confiabilidade dos itens); e a correlação de Spearman, método não paramétrico, que mensura a intensidade, grau de relação entre duas variáveis e a sua força. Então, quanto mais próximo do valor 1, maior a correlação entre as dimensões (HAIR et al., 2009). Leva-se em conta ainda a perspectiva de Bisquerra, Sarriera e Matínez (2009), de que o coeficiente de Spearman tem variações entre: 0,01 e 0,19 - associações muito baixas; 0,20 e 0,39 - baixas; 0,40 e 0,59 - moderadas; 0,60 e 0,79 - altas; 0,80 e 0,99 - muito altas; e 1 uma correlação perfeita. Para o tratamento dos dados, utilizaram-se os softwares estatísticos Statistical 
Package for the Social Sciences (SPSS) (versão 22.0) e Language and Enviroment for Statistical Computing (R) (versão 3.2.3).

\section{ANÁLISE E DISCUSSÃO DOS RESULTADOS}

\subsection{PERFIL DA AMOSTRA}

Com base na análise dos dados sociodemográficos, ao considerar a amostra de 384 indivíduos, pela Tabela 1 verificam-se as características referentes ao perfil da amostra dos servidores de uma universidade pública.

Tabela 1 Dados sociodemográficos

\begin{tabular}{|c|c|c|c|}
\hline Variáveis & Categorias & $(N=384)$ & $(\%)$ \\
\hline \multirow{3}{*}{ Sexo } & Homem & 215 & 56,0 \\
\hline & Mulher & 169 & 44,0 \\
\hline & Total & 384 & 100,0 \\
\hline \multirow{6}{*}{ Estado Civil } & Solteiro(a) & 126 & 32,8 \\
\hline & Casado(a) & 206 & 53,6 \\
\hline & União Estável & 26 & 6,8 \\
\hline & Separado/Divorciado & 24 & 6,3 \\
\hline & Viúvo & 2 &, 5 \\
\hline & Total & 384 & 100,0 \\
\hline \multirow{7}{*}{ Escolaridade } & $2^{\circ}$ Grau Completo & 4 & 1,0 \\
\hline & Graduação Incompleta & 22 & 5,7 \\
\hline & Graduação Completa & 67 & 17,4 \\
\hline & Especialização & 93 & 24,2 \\
\hline & Mestrado & 81 & 21,1 \\
\hline & Doutorado & 117 & 30,5 \\
\hline & Total & 384 & 100,0 \\
\hline \multirow{6}{*}{ Renda } & Até $\mathrm{R} \$ 2.000$ & 3 & 8 \\
\hline & De $\mathrm{R} \$ 2.001$ a R\$ 5.000 & 143 & 37,2 \\
\hline & De R\$ 5.001 a R\$ 7.000 & 88 & 22,9 \\
\hline & De R $\$ 7.001$ a R $\$ 10.000$ & 76 & 19,8 \\
\hline & Acima de $R \$ 10.000$ & 74 & 19,3 \\
\hline & Total & 384 & 100,0 \\
\hline \multirow{6}{*}{$\begin{array}{l}\text { Responsabilidade } \\
\text { financeira }\end{array}$} & Único responsável & 80 & 20,8 \\
\hline & $\begin{array}{l}\text { Principal responsável, mas recebe ajuda de } \\
\text { outras pessoas }\end{array}$ & 97 & 25,3 \\
\hline & $\begin{array}{l}\text { Divide igualmente as responsabilidades com } \\
\text { outra pessoa }\end{array}$ & 136 & 35,4 \\
\hline & Contribui apenas com uma pequena parte & 56 & 14,6 \\
\hline & Não tem nenhuma responsabilidade financeira & 15 & 3,9 \\
\hline & Total & 384 & 100,0 \\
\hline \multirow{3}{*}{ Função } & Técnico Administrativo & 239 & 62,2 \\
\hline & Docente & 145 & 37,8 \\
\hline & Total & 384 & 100,0 \\
\hline \multirow{3}{*}{ Filhos } & Sim & 190 & 49,5 \\
\hline & Não & 194 & 50,5 \\
\hline & Total & 384 & 100,0 \\
\hline
\end{tabular}

Fonte: Dados da pesquisa. 


\section{OS VALORES RELATIVOS AO TRABALHO E O ENTRINCHEIRAMENTO ORGANIZACIONAL DOS \\ SERVIDORES DE UMA UNIVERSIDADE PÚBLICA \\ DOI: http://dx.doi.org/10.5007/1983-4535.2018v11n3p166}

Identifica-se predominantemente servidores do sexo masculino (56\%) e casados $(53,6 \%)$. Em relação à escolaridade, prevalece o doutorado (30,5\%), e isto possibilita inferir um alto grau de instrução e escolaridade para esses servidores, uma vez que apenas $6,7 \%$ não tem graduação completa. Quanto à renda, ocorre predominância do salário variando de $\mathrm{R} \$$ 2.001 a R \$ 5.000, representando, então, 37,2\%; e de R\$ 5.001 a R 7.000 com 22,9\%. Menos de $1 \%$ da amostra recebe um valor inferior a $\mathrm{R} \$ 2.000$, o que se indica um padrão relativamente alto, considerando a média salarial dos trabalhadores brasileiros.

No tocante à responsabilidade financeira dos servidores, predomina-se a divisão igual da responsabilidade com outra pessoa $(35,4 \%)$, em seguida se tem o indivíduo da amostra como o principal responsável, porém recebendo ajuda de outras pessoas $(25,3 \%)$. Além disso, o indivíduo sendo considerado como único responsável representa $20,8 \%$ da amostra. As funções dos indivíduos segmentam-se em técnico administrativo $(62,2 \%)$ e docente $(37,8 \%)$ de uma universidade pública do Estado do Ceará.

A idade média desses servidores é de 36 anos, variando entre a mínima 23 e a máxima 75 anos. O tempo de serviço médio é de 9 anos, considerando que esse tempo teve uma variação de 2 meses até 50 anos. Ao considerar funções de liderança, 34,6\% exercem tal função, enquanto que $65,4 \%$ não estão nessas funções. E, ao considerar algum tipo de gratificação ou cargo em comissão, apenas 22,4\% apresentam gratificação.

\subsection{DIMENSÕES DOS VALORES RELATIVOS AO TRABALHO}

Ao levar em conta os valores relativos ao trabalho, segmentados em 6 dimensões (PORTO; PILATI, 2010), observa-se a Tabela 2, que mostra o mínimo, máximo, desviopadrão, número de itens da dimensão e Alfa de Cronbach - que permite indicar a confiabilidade interna dos itens para cada dimensão, e isto expressa o grau de confiabilidade das respostas do questionário.

Percebe-se que, entre as dimensões dos valores relativos ao trabalho, a segurança foi a mais recorrente para os servidores $(M=4,067)$, com convergência entre os indivíduos ( $\mathrm{sd}=$ 3,164 ), variando entre 3,557 e 4,284 , e isto indica que a segurança foi considerada entre importante e muito importante para os servidores analisados. Além disso, pode-se considerar o segundo maior Alfa de Cronbach $(\alpha=0,867)$, que é a média das correlações entre os itens que fazem parte de um instrumento, sendo, então, a dimensão que apresentou maior confiabilidade interna entre os itens (CRONBACH et al., 1972). A segurança refere-se ao 
quanto o servidor percebe integridade moral, física e intelectual (PORTO; PILATI, 2010; SCHWARTZ, 2012).

Tabela 2 Valores relativos ao trabalho

\begin{tabular}{|c|c|c|c|c|c|c|}
\hline Dimensão & $\begin{array}{l}\text { Média } \\
\text { (M) }\end{array}$ & Mínimo & Máximo & $\begin{array}{l}\text { Desvio- } \\
\text { padrão } \\
\text { (sd) }\end{array}$ & $\begin{array}{c}\mathrm{N}^{\mathrm{o}} \text { de } \\
\text { itens (n) }\end{array}$ & $\begin{array}{c}\text { Alfa de } \\
\text { Cronbach } \\
(\alpha)\end{array}$ \\
\hline $\begin{array}{l}\text { Universalismo/Benevolência } \\
\text { (UB) }\end{array}$ & 3,994 & 3,849 & 4,138 & 3,557 & 5 & 0,875 \\
\hline Realização (RE) & 3,616 & 3,341 & 3,815 & 3,359 & 5 & 0,857 \\
\hline $\begin{array}{l}\text { Autodeterminação/Estimulação } \\
\text { (AE) }\end{array}$ & 3,268 & 1,346 & 3,878 & 5,371 & 10 & 0,824 \\
\hline Conformidade (CO) & 3,454 & 2,862 & 3,878 & 2,610 & 4 & 0,723 \\
\hline Poder (PO) & 3,557 & 3,557 & 3,557 & 2,891 & 5 & 0,700 \\
\hline Segurança (SE) & 4,067 & 3,557 & 4,284 & 3,164 & 5 & 0,867 \\
\hline
\end{tabular}

Fonte: Dados da pesquisa.

Além disso, universalismo/benevolência foi a outra dimensão mais recorrente para os servidores $(\mathrm{M}=3,994)$, com convergência entre os indivíduos $(\mathrm{sd}=3,557)$ e variando entre 3,849 e 4,138, em que foi considerado, ainda, o maior Alfa de Cronbach $(\alpha=0,875)$. Diante disso, pode-se inferir que a busca pelo bem-estar, lealdade, amizade verdadeira, preocupação com o coletivo, com a comunidade, com o planeta e com a igualdade entre todos foi predominante entre os valores relativos ao trabalho para os servidores investigados (PORTO; PILATI, 2010; SCHWARTZ, 2012).

Em contrapartida, autodeterminação/estimulação foi a dimensão menos recorrente para os servidores $(\mathrm{M}=3,268)$, com convergência entre os indivíduos ( $\mathrm{sd}=5,371)$ e variando entre 1,346 e 3,878, com uma alta consistência interna entre os itens da dimensão, Alfa de Cronbach $(\alpha=0,824)$. Nessa perspectiva, infere-se que autodeterminação/estimulação, que se refere a capacidade de tomar decisões para si e/ou ter autonomia entre seus atos, entre a liberdade de agir, falar e se expressar, bem como a percepção de se ter uma vida estimulante no ambiente de trabalho e variada, foi a dimensão menos recorrente para os servidores (PORTO; PILATI, 2010; SCHWARTZ, 2012).

A conformidade também foi pouco recorrente quando comparada com as outras dimensões dos valores relativos ao trabalho $(\mathrm{M}=3,454)$, com convergência entre os indivíduos ( $\mathrm{sd}=2,610)$ e variando entre 2,862 e 3,878, com uma consistência interna Alfa de Cronbach $(\alpha=0,723)$ moderada, porém aceitável. Nesse sentido, o comportamento do indivíduo de acordo com as normas dos grupos, com mais tradição e subordinação com as 
expectativas da sociedade, foi a segunda dimensão menos importante no tocante aos valores relativos ao trabalho (PORTO; PILATI, 2010; SCHWARTZ, 2012).

\subsection{DIMENSÕES DO ENTRINCHEIRAMENTO ORGANIZACIONAL}

Em relação ao entrincheiramento organizacional, a Tabela 3 mostra as três dimensões do entrincheiramento organizacional, considerando média, mínimo, máximo, desvio-padrão, número de itens da dimensão e Alfa de Cronbach .

Tabela 3 Entrincheiramento organizacional

\begin{tabular}{lcccccccc}
\hline \multicolumn{2}{c}{ Dimensão } & & $\begin{array}{c}\text { Média } \\
(\mathrm{M})\end{array}$ & Mínimo & Máximo & $\begin{array}{c}\text { Desvio- } \\
\text { padrão (sd) }\end{array}$ & $\begin{array}{c}\mathrm{N}^{\mathrm{o}} \text { de } \\
\text { itens (n) }\end{array}$ & $\begin{array}{c}\text { Alfa de } \\
\text { cronbach } \\
(\alpha)\end{array}$ \\
\hline $\begin{array}{l}\text { Ajustamentos à̀ } \\
\text { (APS) }\end{array}$ & posição & social & 2,107 & 1,688 & 2,648 & 4,895 & 6 & 0,787 \\
$\begin{array}{l}\text { Arranjos burocráticos } \\
\text { (ABI) }\end{array}$ & impessoais & 1,944 & 1,729 & 2,266 & 5,506 & 6 & 0,889 \\
Limitação de alternativas (LA) & 3,148 & 2,695 & 3,581 & 5,820 & 6 & 0,836 \\
\hline
\end{tabular}

Fonte: Dados da pesquisa.

Verifica-se que a limitação de alternativas foi a dimensão mais recorrente do entrincheiramento organizacional $(\mathrm{M}=3,148)$, com convergência entre os indivíduos ( $\mathrm{sd}=$ $5,820)$ e variando entre 2,695 e 3,581, apresentando o segundo maior Alfa de Cronbach $(\alpha=$ 0,836), que se refere à percepção do indivíduo frente às restrições de empregabilidade, o que faz com que o servidor se sinta preso, isto é, entrincheirado, sem que tenha alternativas caso saísse da organização a qual trabalha, seja pela falta de oportunidades ou por outros fatores, como idade, limitação de conhecimento ou por não ser aceito em outro ambiente profissional - que podem reduzir a empregabilidade desse servidor em outras organizações (BASTOS et al., 2013; BECKER, 1960; CARSON; CARSON; BEDEIAN, 1995).

Em contrapartida, a dimensão arranjos burocráticos impessoais foi menos recorrente na percepção dos servidores $(\mathrm{M}=1,944)$, com convergência entre os indivíduos $(\mathrm{sd}=5,506)$ e variando entre 1,729 e 2,266, apresentando o maior Alfa de Cronbach $(\alpha=0,889)$, dado que esta dimensão representa a percepção do indivíduo frente aos ganhos materiais, estabilidade funcional e financeira, bem como os benefícios perdidos com a saída da organização. Portanto, o desligamento do indivíduo da organização resultaria, consequentemente, em uma perda considerável da soma de capital que possui, destacando, ainda, a inexistência de férias e 
feriados pagos, participação nos lucros, assistência médica, previdência privada, aposentadoria, entre outros (BASTOS et al., 2013; BECKER, 1960).

\subsection{VALORES RELATIVOS AO TRABALHO E ENTRINCHEIRAMENTO ORGANIZACIONAL ENTRE DOCENTES E TÉCNICOS ADMINISTRATIVOS}

Observa-se pela Tabela 4 a diferença entre os técnicos administrativos e os docentes, levando-se em conta os valores relativos ao trabalho e o entrincheiramento organizacional, em que foram utilizados os testes $t$ e de Mann-Whitney para avaliar a diferença entre as médias entre os dois grupos (técnicos administrativos e docentes). Para esses testes, optou-se pela significância de 5\% - conforme sugerido por Hair et al. (2009), buscando-se verificar se há diferenças estatisticamente significantes entre esses dois grupos. A amostra foi composta por 239 técnicos administrativos e 145 docentes, totalizando 384 servidores públicos.

Tabela 4 valores relativos ao trabalho e entrincheiramento organizacional pelo cargo

\begin{tabular}{|c|c|c|c|c|c|}
\hline Dimensões & Cargo & Média & $\begin{array}{l}\text { Desvio } \\
\text { Padrão }\end{array}$ & Teste $\mathrm{t}$ & $\begin{array}{l}\text { Teste de Mann- } \\
\text { Whitney }\end{array}$ \\
\hline Universalismo/ & Téc. Administrativo & 3,9582 & ,71474 & \multirow[b]{2}{*}{,266 } & \multirow{2}{*}{, 075} \\
\hline Benevolência (UB) & Docente & 4,0552 & ,88803 & & \\
\hline \multirow{2}{*}{ Poder (PO) } & Téc. Administrativo & 2,1715 & ,62162 & \multirow{2}{*}{, 031} & \multirow{2}{*}{,028 } \\
\hline & Docente & 2,3241 & ,69605 & & \\
\hline \multirow{2}{*}{ Realização (RE) } & Téc. Administrativo & 3,6234 & ,71628 & \multirow{3}{*}{ 743 } & \multirow[b]{2}{*}{ 680 } \\
\hline & Docente & 3,6483 & ,72199 & & \\
\hline \multirow{2}{*}{ Segurança (SE) } & Téc. Administrativo & 4,1632 & ,70602 & & \multirow{3}{*}{,040 } \\
\hline & Docente & 4,0000 & ,73598 & \multirow[t]{2}{*}{, 033} & \\
\hline \multirow{2}{*}{ Conformidade (CO) } & Téc. Administrativo & 3,6402 & ,65161 & & \\
\hline & Docente & 3,4552 & ,77262 & \multirow{2}{*}{, 017} & \multirow[t]{2}{*}{,031 } \\
\hline \multirow{2}{*}{$\begin{array}{l}\text { Autodeterminação/Estim } \\
\text { ulação (AE) }\end{array}$} & Téc. Administrativo & 3,2803 &, 55085 & & \\
\hline & Docente & 3,4966 & ,61378 & \multirow[t]{2}{*}{, 001} & \multirow[t]{2}{*}{,000 } \\
\hline \multirow{4}{*}{$\begin{array}{l}\text { Ajustamentos à posição } \\
\text { social (APS) } \\
\text { Limitação de alternativas } \\
\text { (LA) }\end{array}$} & Téc. Administrativo & 2,0711 & ,81938 & & \\
\hline & Docente & 2,3931 & ,96679 & \multirow{2}{*}{,001 } & \multirow[t]{2}{*}{, 001} \\
\hline & Téc. Administrativo & 2,0042 & ,97661 & & \\
\hline & Docente & 1,9448 & ,96306 & ,562 & \multirow{3}{*}{$\begin{array}{l}\text { 533 } \\
\text {,008 }\end{array}$} \\
\hline \multirow{2}{*}{$\begin{array}{l}\text { Arranjos burocráticos } \\
\text { impessoais (ABI) }\end{array}$} & Téc. Administrativo & 3,3305 & ,99344 & \multirow{2}{*}{, 011} & \\
\hline & Docente & 3,0621 & ,99457 & & \\
\hline
\end{tabular}

Fonte: Dados da pesquisa.

Ocorreram diferenças estatisticamente significantes entre os docentes e os técnicos administrativos nas dimensões Poder, Conformidade, Autodeterminação/Estimulação, Ajustamentos à posição social e Arranjos burocráticos impessoais, as quais apresentaram, tanto pelo teste t como pelo teste de Mann-Whitney, valores inferiores a 0,05. Em relação aos valores relativos ao trabalho, comparando os docentes com os técnicos administrativos, ressaltam-se que os docentes sentem mais poder (2,3241 versus 2,1715$)$, e isto mostra que os 
docentes têm mais influência e busca pelo status, como autoridade, riqueza, reconhecimento social e autoridade; ao compará-los com os técnicos administrativo.

Todavia, os técnicos administrativos revelaram mais segurança $(4,1632$ versus 4,0000$)$ e conformidade $(3,6402$ versus 3,4552$)$ ao compará-los com os docentes, podendo-se inferir que eles percebem que detêm mais segurança familiar, senso de pertencimento, reciprocidade de favores e saúde do que os docentes.

Além disso, ao considerar o entrincheiramento organizacional, predomina o ajustamento à posição social para os docentes (2,3931 versus 2,0711$)$, que se refere aos investimentos feitos para a adaptação à posição social, visto que caso saiam, esses investimentos são perdidos; e os arranjos burocráticos impessoais para os técnicos administrativos (3,3305 versus 3,0621), e isto evidencia que os técnicos administrativos percebem maiores restrições quanto à empregabilidade, o que faz com que se sintam mais presos na universidade a qual trabalham.

\subsection{RELAÇÃO ENTRE VALORES RELATIVOS AO TRABALHO E ENTRINCHEIRAMENTO ORGANIZACIONAL}

Com o intuito de investigar se há relações entre os valores relativos ao trabalho e o entrincheiramento organizacional, utiliza-se a correlação de Spearman (visto que os dados são não paramétricos), e assim mensura-se o efeito entre as dimensões dos valores relativos ao trabalho e as dimensões do entrincheiramento organizacional. Ademais, verificam-se o sigma entre as duas extremidades, a soma dos quadrados e produtos cruzado e o número de respostas utilizadas para a comparação.

Vê-se, ainda, que são incluídas duas observações referentes à significância, no nível 0,01 e 0,05; sendo representadas na análise da correlação de Spearman, respectivamente, com dois asteriscos e um asterisco, medindo a força da relação - ou seja, o efeito que uma dimensão tem sobre a outra.

A correlação que apresentou maior relação foi entre realização e ajustamento à posição social $(\mathrm{r}=0,164)$, considerada uma associação muito baixa. $\mathrm{O}$ ajustamento à posição social refere-se à percepção de perda dos investimentos feitos nas condições necessárias à adaptação do indivíduo ao ambiente de trabalho e ao seu reconhecimento na organização. Isto inclui capacitação, tempo para aprender processos e relacionamentos construídos com os colegas (BASTOS et al., 2013; RODRIGUES; BASTOS, 2012). Enquanto isso, a realização é o quanto o servidor busca do sucesso e reconhecimento profissional, levando-se em conta as 
regras do grupo. Portanto, são os servidores que prezam por atividades que demonstrem suas competências, que as façam se sentir bem-sucedidos e, por meio dessas atividades, venham a ser reconhecidos pelo resultado do seu trabalho.

Tabela 5 Correlação entre os valores do trabalho e o entrincheiramento organizacional

\begin{tabular}{|c|c|c|c|c|c|c|c|}
\hline \multicolumn{2}{|c|}{$\begin{array}{l}\text { Valores relativos ao } \\
\text { trabalho/ } \\
\text { Entricheiramento } \\
\text { Organizacional }\end{array}$} & $\begin{array}{l}\text { Universalism } \\
\text { o } \\
\text { /Benevolência }\end{array}$ & Realização & $\begin{array}{c}\text { Autodeter } \\
\text { minação/ } \\
\text { Estimulaçã } \\
\text { o }\end{array}$ & Conformidade & Poder & $\begin{array}{c}\text { Segura } \\
\text { nça }\end{array}$ \\
\hline \multirow{2}{*}{$\begin{array}{l}\text { Ajustament } \\
\text { os à posição } \\
\text { social }\end{array}$} & $\begin{array}{l}\text { Coeficient } \\
\text { e }\end{array}$ &,- 006 &, $164^{* *}$ &, 024 &,- 046 & ,002 &,- 075 \\
\hline & Sig. & ,909 &, 001 &, 635 & ,371 & ,974 &, 144 \\
\hline \multirow{2}{*}{$\begin{array}{l}\text { Arranjos } \\
\text { burocrático } \\
\mathrm{s} \\
\text { impessoais } \\
\end{array}$} & $\begin{array}{l}\text { Coeficient } \\
\text { e }\end{array}$ &,$- 130^{*}$ & ,022 &,- 062 &,- 035 &,- 070 &,$- 188^{* *}$ \\
\hline & Sig. & ,010 & ,667 & ,222 & ,491 & ,170 &, 000 \\
\hline \multirow{2}{*}{$\begin{array}{l}\text { Limitação } \\
\text { de } \\
\text { alternativas }\end{array}$} & $\begin{array}{l}\text { Coeficient } \\
\mathrm{e}\end{array}$ &,- 028 &,- 052 & ,036 &, $155^{* *}$ &, $104^{*}$ &,$- 140^{* *}$ \\
\hline & Sig. & ,587 & ,313 & ,478 & ,002 &, 041 &, 006 \\
\hline
\end{tabular}

Fonte: Dados da pesquisa.

*. A correlação é significativa no nível 0,05 (2 extremidades).

**. A correlação é significativa no nível 0,01 (2 extremidades).

Todas as outras correlações apresentaram baixa associação e, além disso, indicaram correlações negativas, isto é, quando uma variável aumenta, a outra diminui. Entretanto, essas correlações negativas foram consideras muito baixas. As correlações negativas e muito baixas encontradas foram entre arranjos burocráticos impessoais e universalismo/benevolência $(r=$ 0,130), que está voltado para a preocupação com o bem-estar da sociedade e dos colegas de trabalho (SCHWARTZ, 2012). Portanto, são os servidores que valorizam a colaboração para o desenvolvimento da comunidade, o combate a injustiças, que gostam de se sentir útil e têm compromisso social; e arranjos burocráticos impessoais e segurança $(r=-0,188)$, que se refere a busca de segurança financeira e estabilidade no emprego pelos servidores.

Ademais, foram verificadas outras correlações, entre limitações de alternativas, que se referem às percepções de restrições de empregabilidade, destacando-se o quanto o servidor possa se sentir preso na organização; e conformidade $(r=0,155)$, que são as restrições de ações e posturas que podem violar as expectativas das normas sociais dos grupos - isto é, ir contra ao grupo. Entre limitações de alternativas e poder, que é o quanto o servidor se presa em sua posição social dentro do sistema social $(r=0,104)$; e entre limitações de alternativas e 
segurança $(\mathrm{r}=-0,140)$ (PORTO; PILATI, 2010; RODRIGUES; BASTOS, 2012; SCHWARTZ, 2012).

Esses achados mostram que os servidores que percebem a valorização das atividades, considerando o sucesso pessoal e reconhecimento social, diante de competência, sucesso, inteligência, ambição e reconhecimento por parte dos colegas, tendem, contudo, a não considerar que teriam perdas financeiras caso saíssem da universidade a qual trabalha. Destarte, quanto mais este servidor motiva outras pessoas, são honestos e prestativos e voltados à coletividade do grupo, com união e igualdade, menos são percebidos os ganhos materiais, estabilidade financeira e funcional e benefícios que podem ser perdidos com a saída dos servidores.

Além disso, os servidores que apreciam os desafios constantes e valorizam atividades arriscadas, que lhes permitam conhecer lugares e pessoas novas, demonstraram predisposição menor ao considerarem que perderiam benefícios caso fossem trabalhar em outra instituição ou que essa mudança poderia, de alguma forma, afetar a sua estabilidade financeira.

\section{CONCLUSÕES}

A proposta deste estudo foi analisar a relação entre os valores relativos ao trabalho e o entrincheiramento organizacional dos servidores de uma universidade pública. Adicionalmente, pretendeu-se comparar os valores relativos ao trabalho e o entrincheiramento organizacional entre os docentes e os técnicos administrativos.

Diante disso, foram observados que, na perspectiva dos servidores, dentre as dimensões dos valores relativos ao trabalho, as dimensões segurança e universalismo/benevolência foram as mais recorrentes, e isto mostra que os servidores sentiram mais integridade moral, física e intelectual, enfatizando a segurança financeira e familiar; e pretendem motivar outras pessoas a buscarem bem-estar, considerando a preocupação com o grupo e com o planeta. Por outro lado, as dimensões menos recorrentes foram autodeterminação/estimulação e conformidade, o que se pôde inferir menor percepção dos servidores em relação à autonomia e tomada de decisão, criatividade e excitação.

No tocante ao entrincheiramento organizacional, constatou-se que a dimensão mais recorrente foi limitação de alternativas, que se refere a percepção do servidor frente às restrições de empregabilidade, que faz com que o servidor se sinta, de certo modo, entrincheirado (preso) à organização. Entretanto, a dimensão menos recorrente foi arranjos 
burocráticos impessoais, em que se pôde ressaltar que os servidores não perceberam tanto os benefícios perdidos com a saída da organização, como estabilidade funcional, financeira e material.

Ao comparar os docentes com os técnicos administrativos de uma universidade, ressaltou-se que os técnicos administrativos percebem menos influência, autoridade, riqueza e reconhecimento social do que os docentes. Em contrapartida, os técnicos administrativos demonstraram mais segurança pessoal do que os docentes. Ainda assim, os técnicos administrativos perceberam maiores restrições quanto à empregabilidade, sentindo-se, então, mais presos à universidade.

De modo geral, foram constatadas relações entre ajustamento à posição social e realização, referente ao reconhecimento mediante a competência e eficácia; entre arranjos burocráticos impessoais e universalismo e benevolência, que diz respeito à preocupação com o grupo e a busca do bem-estar das pessoas próximas; e entre limitação de alternativas e conformidade, que se refere à autodisciplina, educação e respeito.

Todavia, houveram relações negativas entre arranjos burocráticos impessoais e segurança, e isto mostra que quanto maior o efeito dos arranjos burocráticos impessoais, menor a segurança, que se refere à segurança familiar, física e moral. Também detectou-se relação negativa entre limitação de alternativas e segurança.

Os resultados deste estudo mostraram aspectos relevantes para a compreensão da motivação dos servidores na universidade e que, consequentemente, contribui para o desenvolvimento de ações que possam fortalecer vínculos positivos e minimizar vínculos negativos do servidor com a universidade. Por meio do mapeamento dos valores, é possível direcionar as práticas de Recursos Humanos para grupos específicos que se queira trabalhar ou, até mesmo, personalizar algumas ações, e isto contribui para o estabelecimento de políticas e práticas organizacionais que possam ampliar a motivação dos funcionários, impactando, consequentemente, nos resultados organizacionais.

Ao conhecer o perfil dos servidores entrincheirados, é possível ajustar as relações de reciprocidade que existem entre empregado e empregador, de modo a alinhar os valores organizacionais aos individuais. Ademais, esta pesquisa busca contribuir academicamente para um melhor entendimento de como esses constructos podem relacionar-se com outros, a fim de suplantar a lacuna da literatura que alinha os valores relativos ao trabalho ao entrincheiramento organizacional dos servidores (técnicos administrativos e docentes) de uma 
universidade pública.

Para pesquisas futuras, sugere-se aprofundar, por meio de entrevistas em profundidade, com o uso do método da análise de conteúdo, os valores relativos ao trabalho e o entrincheiramento organizacional dos servidores de outras universidades públicas do Brasil.

\section{REFERÊNCIAS}

ANDRADE, T.; ESTIVALETE, V. D. F. B.; FALLER, L. P.; COSTA V. F. Valores relativos ao trabalho e âncoras de carreira: a ótica de discentes do ensino superior nas modalidades presencial e à distância. Revista Gestão Universitária na América Latina-GUAL, v. 11, n. 1, p. 24-47, 2018.

ANDRADE, T.; COSTA, V. F.; ESTIVALETE, V. D. F. B.; LENGLER, L. Organizational citizenship behaviors: a glimpse in the light of values and job satisfaction. Revista brasileira de gestão de negócios, v. 19, n. 64, p. 236-262, 2017.

BAIOCCHI, A. C.; MAGALHÃES, M. Relações entre processos de comprometimento, entrincheiramento e motivação vital em carreiras profissionais. Revista Brasileira de Orientação Profissional, v. 5, n. 1, p. 63-69, 2004.

BALSAN, A. L. G.; LOPES, L. F. D.; ALVES, J. N; VIZZOTTO, F. B.; COSTA, V. M. F. Impacto do treinamento, comprometimento e entrincheiramento organizacionais em servidores de uma universidade pública. Revista Gestão Universitária na América LatinaGUAL, v. 9, n. 1, p. 143-164, 2016.

BASTOS, A. V. B.; RODRIGUES, A. C. A.; MOSCON, D. C. B.; COSTA e SILVA, E. E.; PINHO, A. P. M. Comprometimento no trabalho: fundamentos para a gestão de pessoas. In: BORGES, L. O.; MOURÃO, L. O trabalho e as organizações: atuações a partir da psicologia. Artmed: p. 279-310, 2013.

BECKER, H. S. Notes on the concept of commitment. American journal of Sociology, v. 66, n. 1, p. 32-40, 1960.

BISQUERRA, R.; SARRIERA, J. C.; MATÍNEZ, F. Introdução à estatística: enfoque informático com o pacote estatístico SPSS. Bookman Editora, 2009.

BLAU, G. On assessing the construct validity of two multidimensional constructs: Occupational commitment and occupational entrenchment. Human Resource Management Review, v. 11, n. 3, p. 279-298, 2001.

BLAU, G.; HOLLADAY, B. E. Testing the discriminant validity of a four-dimensional occupational commitment measure. Journal of Occupational and Organizational Psychology, v. 79, n. 4, p. 691-704, 2006. 
CAMMAROSANO, M.; SANTOS, F. C. A.; ROJAS, F. A. Valores relativos ao trabalho de pesquisadores em uma organização brasileira. RAE - Revista de Administração de Empresas, v. 54, n. 4, p. 445-457, 2014.

CAMARA, S. M. A.; GUERRA, N. M. D. C. P.; GURGEL, F. F. análise estatística dos valores relativos ao trabalho e o comprometimento organizacional. Connexio, v. 4, n. 2, p. 123-139, 2015.

CARSON, K. D.; BEDEIAN, A. G. Career commitment: Construction of a measure and examination of its psychometric properties. Journal of Vocational Behavior, v. 44, n. 3, p. 237-262, 1994.

CARSON, K. D.; CARSON, P. P.; BEDEIAN, A. G. Development and construct validation of a career entrenchment measure. Journal of Occupational and Organizational

Psychology, v. 68, n. 4, p. 301-320, 1995.

CARVAlHO, P.; ALVES, F. J. O.; PEIXOTO, A. L. A.; BASTOS, A. V. B.

Comprometimento afetivo, de continuação e entrincheiramento organizacional: estabelecendo limites conceituais e empíricos. Psicologia: Teoria e Prática, v. 13, n. 2, p. 127-141, 2011.

CARVALHO, V. D.; BOAS, V.; MARTINHO, E.; GUERRA, A. C.; FREITAS, T. A. Valores do trabalho e incubação de empreendimentos solidários: a experiência da Associação Terra do Marolo. Psicologia \& Sociedade, v. 26, n. 2, p. 449-460, 2014.

COLLIS, J.; HUSSEY, R. Pesquisa em administração: um guia prático para alunos de graduação e pós-graduação. Porto Alegre: Bookman, 2005.

COOPER, D. R.; SCHINDLER, P. S. Métodos de Pesquisa em Administração. $12^{\text {a }}$ Edição. McGraw Hill Brasil, 2016.

CRONBACH, L. J.; GLESER, G. C.; NANDA, H.; RAJARATNAM, N. The dependability of behavioral measurements: Theory for generalizability of scores and profiles. New York: John Wiley. 1972

FERREIRA, S. D.; FERRAZ, S. F. S.; COSTA, J. S. Valores do trabalho e satisfação no serviço público brasileiro: estudo em uma seccional da justiça federal. In: ENCONTRO DA ANPAD, 39, 2015, Belo Horizonte. Anais... Belo Horizonte: ANPAD, 2015.

HAIR, J. F.; , BLACK, W. C.; BABIN, B. J.; ANDERSON, R. E.; TATHAM, R. L. Análise multivariada de dados. Bookman Editora, 2009.

JIN, J.; ROUNDS, J. Stability and change in work values: A meta-analysis of longitudinal studies. Journal of Vocational Behavior, v. 80, n. 2, p. 326-339, 2012.

KLEIN, H. J.; MOLLOY, J. C.; COOPER, J. T. Conceptual foundations: Construct definitions and theoretical representations of workplace commitments. Commitment in organizations: Accumulated wisdom and new directions, v. 1, p. 3-36, 2009. 
MAGALHÃES, M. O.; GOMES, W. B. Personalidades vocacionais e processos de carreira na vida adulta. Psicologia em Estudo, v. 12, n. 1, p. 95-103, 2007.

MARTINS, S. H. B. M.; SANT'ANNA, A. S. Valores individuais e comprometimento organizacional: um estudo com o corpo docente de instituição de ensino superior. Revista Gestão Universitária na América Latina-GUAL, v. 7, n. 3, p. 227-246, 2014.

MEIRELES, A. Q.; LEMOS, A. H. C.; BALASSIANO, M. Fico porque preciso: entrincheiramento organizacional e satisfação no trabalho para empregados de uma empresa de energia brasileira. Anais... Encontro de Gestão de Pessoas e Relações de Trabalho, 5, 2015, Salvador. Salvador: ANPAD, 2015.

MEYER, J. P.; ALLEN, N. J. A three-component conceptualization of organizational commitment. Human Resource Management Review, v. 1, n. 1, p. 61-89, 1991.

MINER, J. B. Organizational behavior 1: Essential theories of motivation and leadership. Routledge, 2015.

MOWDAY, R. T.; PORTER, L. W.; STEERS, R. M. Employee-organization linkages: The psychology of commitment, absenteeism, and turnover. Academic press, 2013.

PAIVA, M. B. M.; FERRAZ, F. S. de S. Hierarquia de Valores entre Grupos Geracionais em uma Pró-Reitoria de Instituição Federal de Ensino Superior: uma Análise através da Escala EVT. Anais... SEMEAD, 16, 2013, São Paulo. São Paulo: FEA USP, 2013.

PORTO, J. B,; PILATI, R. Escala revisada de valores relativos ao trabalho-EVT-R. Psicologia: Reflexão e Crítica, v. 23, n. 1, p. 73-82, 2010.

PORTO, J. B.; TAMAYO, A.Valores do trabalho. In: SIQUEIRA, Mirlene Maria Matias. Medidas do comportamento organizacional: ferramentas de diagnóstico e de gestão. Porto Alegre: Artmed, 2008.

PORTO, J. B.; TAMAYO, A. Estrutura dos valores pessoais: a relação entre valores gerais e laborais. Psicologia: Teoria e Pesquisa, v. 23, n. 1, p. 063-070, 2012.

RODRIGUES, A. C. A.; BASTOS, A. V. B. Problemas conceituais e empíricos na pesquisa sobre comprometimento organizacional: uma análise crítica do modelo tridimensional de J. Meyer e N. Allen. Revista Psicologia Organizações e Trabalho, v. 10, n. 2, p. 129-144, 2010.

RODRIGUES, A. C. A.; BASTOS, A. V. B. Entrincheiramento organizacional: construção e validação da escala. Psicologia: Reflexão e Crítica, v. 25, n. 4, p. 688-700, 2012.

RODRIGUES, A. P .G.; BASTOS, A. V. B. Os Vínculos de Comprometimento e Entrincheiramento Presentes nas Organizações Públicas. Revista de Ciências da Administração, v. 15, n. 36, p. 143-158, 2013. 
RODRIGUES, A. C. A.; GONDIM, S. M. G.; BASTOS, A. V. B.; SAKAMOTO, R. Como se constroem e se desenvolvem o entrincheiramento e o comprometimento com a organização: análise qualitativa de diferentes trajetórias profissionais In: Proceedings of the 37th Annual Meeting of the Brazilian Academy of Management. 2013.

SCHEIBLE, A. C. F.; BASTOS, A. V. B. An examination of human resource management practices' influence on Organizational Commitment and Entrenchment. BAR-Brazilian Administration Review, v. 10, n. 1, p. 57-76, 2013.

SCHWARTZ, S. H. Universals in the content and structure of values: Theoretical advances and empirical tests in 20 countries. Advances in experimental social psychology, v. 25, p. 165, 1992.

SCHWARTZ, S. H. An overview of the Schwartz theory of basic values. Online readings in Psychology and Culture, v. 2, n. 1, p. 11, 2012.

SILVA, P. M. M.; LIMA, A. N. C.; LEONE, N. M. C. P. Entrincheiramento organizacional: percepção de empregados de uma agência bancária. Revista de Administração IMED, v. 5, n. 2, p. 111-120, 2015.

SILVA, R. C. D.; COSTA, V. M. F.; TOMAZZONI, G. C.; LOPES, L. F. D.; SANTOS, A. S. Relação do modelo agency-community e os vínculos organizacionais. Revista de Administração FACES Journal, v. 16, n. 2, p. 25-44, 2017.

SIQUEIRA, M. M. M.; PADOVAM, V. A. R. Bases teóricas de bem-estar subjetivo, bemestar psicológico e bem-estar no trabalho. Psicologia: Teoria e Pesquisa, v. 24, n. 2, p. 201 209, 2008.

SOLINGER, O. N.; OLFFEN, W. V.; ROE, R. A. Beyond the three-component model of organizational commitment. Journal of Applied Psychology, v. 93, n. 1, p. 70, 2008.

SOUSA, J. M.; PORTO, J. B. Do Work Values Predict Preference for Organizational Values?. Psico-USF, v. 21, n. 1, p. 135-145, 2016.

TAMAYO, A.; PORTO, B. J. Escala de valores relativos ao trabalho. Psicologia: Teoria e Pesquisa, v. 19, n. 2, p. 145-152, 2003.

TECCHIO, E. L.; MELO, P. A.; NUNES, T. S.; TOSTA, H. T. Cooperação universidadesegmento empresarial: a realidade da Universidade Federal de Santa Catarina.

Desenvolvimento em Questão, v. 11, n. 22, p. 173-207, 2013. 